\title{
Children's Sleep Comic: development of a new diagnostic tool for children with sleep disorders
}

This article was published in the following Dove Press journal:

Nature and Science of Sleep

29 August 2012

Number of times this article has been viewed

\author{
Barbara Schwerdtle' \\ Julia Kanis' \\ Lena Kahl' \\ Andrea Kübler ${ }^{1,2}$ \\ Angelika A Schlarb ${ }^{3,4}$ \\ 'Institute of Psychology, Department \\ of Psychology I, University of \\ Würzburg, Würzburg, ${ }^{2}$ Institute of \\ Medical Psychology and Behavioral \\ Neurobiology, ${ }^{3}$ Faculty of Science, \\ Clinical and Developmental \\ Psychology, University of Tübingen, \\ Tübingen, ${ }^{4}$ Department of Clinical \\ Psychology and Psychotherapy, \\ University of Koblenz-Landau, \\ Landau, Germany
}

Background: A solid diagnosis of sleep disorders in children should include both self-ratings and parent ratings. However, there are few standardized self-assessment instruments to meet this need. The Children's Sleep Comic is an adapted version of the unpublished German questionnaire "Freiburger Kinderschlafcomic" and provides pictures for items and responses. Because the drawings were outdated and allowed only for qualitative analysis, we revised the comic, tested its applicability in a target sample, and suggest a procedure for quantitative analysis.

Methods: All items were updated and pictures were newly drawn. We used a sample of 201 children aged 5-10 years to test the applicability of the Children's Sleep Comic in young children and to run a preliminary analysis.

Results: The Children's Sleep Comic comprises 37 items covering relevant aspects of sleep disorders in children. Application took on average 30 minutes. The procedure was well accepted by the children, as reflected by the absence of any dropouts. First comparisons with established questionnaires indicated moderate correlations.

Conclusion: The Children's Sleep Comic is appropriate for screening sleep behavior and sleep problems in children. The interactive procedure can foster a good relationship between the investigator and the child, and thus establish the basis for successful intervention if necessary.

Keywords: children, sleep, sleep disorders, diagnostic, assessment, self-rating

\section{Introduction}

Sleep problems in children are frequently encountered. ${ }^{1}$ Problems falling asleep and maintaining sleep, in particular, appear in childhood. ${ }^{2,3}$ The reported prevalence ranges widely from $5 \%$ to $40 \%,{ }^{1-5}$ which may be due either to specific sleep disorders or, more likely, the diagnostic tools used. Sleep problems do not automatically disappear with age and may persist, ${ }^{6}$ with severe consequences, including hyperactivity, irritability, and aggression ${ }^{7,8}$ and also daytime sleepiness, lack of concentration, memory deficit, and cognitive impairment. ${ }^{9,10}$ Children with sleep disorders are also at higher risk of injuries, ${ }^{11}$ and sleep disorders can lead to depression, anxiety, or overweight. ${ }^{12-18}$ Thus, it is important to take sleep disorders in childhood seriously.

In spite of the high prevalence and the severe consequences, sleep disturbances in childhood are often not recognized. ${ }^{19-21}$ Only 3.3\% of consultations in pediatric medical practices are for sleep problems, ${ }^{21}$ and pediatricians do not routinely ask parents about their children's sleep behavior. In older children and adolescents, parents might not be aware of their children's sleep disorder. The lack of diagnostic instruments adds to the problem. Therefore, it is important to develop further reliable diagnostic tools for sleep disorders in children.
Correspondence: Barbara Schwerdtle Department of Psychology I, University of Würzburg, Marcusstrasse 9-II, Würzburg 97070, Germany

$\mathrm{Tel}+499313180185$

Fax +499313182424

Email barbara.schwerdtle@uniwuerzburg.de 
When assessing sleep disorders in children, parents are usually asked for information. By only interviewing parents, one third of sleep disorders remain unrecognized. In particular, parents do not notice their children's awakening during the night and early in the morning. ${ }^{3}$ Therefore, the child should also be part of the diagnostic process. ${ }^{22,23}$ Children can give more reliable information about certain aspects of their sleep, eg, problems falling asleep and maintaining sleep., ${ }^{4,22}$ The younger the child, the better the parents' knowledge of its sleep habits, and the older the child, the better the child is at providing the information itself. ${ }^{6}$

Despite the importance of sleep disorders in childhood, and the need for a valid diagnosis, there are few standardized diagnostic instruments and most questionnaires only assess the parental view of their child's sleep behavior. Most of the existing self-report questionnaires for sleep disorders in the pediatric age group are for children at least 8 years of age. ${ }^{24}$ To address the need to be able to obtain information directly from the child about his or her sleep, we developed a new diagnostic tool for young children. Using the unpublished German questionnaire "Freiburger Children's Sleep Comic" ${ }^{25}$, we have introduced a new instrument, ie, the Children's Sleep Comic. This comic comprises cartoons for items and response options. Because the drawings were outdated and allowed for qualitative analysis only, we revised the comic, tested its applicability in a target sample, and suggest a procedure for quantitative analysis.

\section{Materials and methods Procedures and samples}

Children were recruited from three primary schools in Germany. Prior to testing, parents received an information letter and gave their written informed consent. The study was conducted according to standard ethical guidelines as defined by the Declaration of Helsinki.

Testing was implemented in the classroom environment. A sample of 201 children aged 5-10 years of age were interviewed using the Children's Sleep Comic. The children were divided into groups of eight, and group interviews were conducted for time and feasibility reasons. Each child sat at a separate table and gave his or her answer in private, so that the children did not influence each other. Two experimenters were present, one who read the questions and answers to the children, and the other who quietly answered any questions from the children. Study questions, cartoons, and answering options were projected onto a wall.

All Children's Sleep Comics were completed and able to be used in the analysis. To be able to relate the
Children's Sleep Comic to established instruments, we also administered the German version of the Children's Sleep Habits Questionnaire (CSHQ-DE) and the German version of the Sleep Self Report (SSR-DE). ${ }^{26,27}$ The CSHQ-DE was completed by 187 parents (return rate 93\%). The SSR-DE was distributed to 139 parents to complete with their children at home and 126 returned the completed questionnaire (return rate $91 \%)$. Parents also provided demographic data.

\section{Revision of the Children's Sleep Comic Layout}

New items for the Children's Sleep Comic were generated according to the sleep disorders in childhood described in the International Classification of Sleep Disorders Second Edition. ${ }^{28}$ All cartoons were newly drawn (see Figure 1 for an example). For each item, one new cartoon was drawn and a statement was assigned. A square at the beginning of each statement had to be marked to indicate "yes". A maximum of five items were shown in two columns per page. The Children's Sleep Comic was provided as a booklet in A5 format, which made it easy for children to handle. It was created as a computer file using Calibri font size 18 .

\section{Content}

In total, 37 items were generated. Items 1-3 assessed age, gender, and family situation (eg, living with both parents) which also helped the children become familiar with the answering mode. At the end of the sleep-related items, additional information was acquired about daytime activities and somatic complaints. The aspects of sleep enquired about were sleep hygiene, quality of sleep, night-time fears, dreaming, awakening in the morning, night-time sweating, night-time bruxism, daytime napping, and chronotype (morning/evening type). The items for sleep hygiene included information about activities before sleeping, place of falling asleep and sleeping through the night, activities in bed before sleeping, sleep onset associations, night-time disturbances, and nighttime awakenings. Items on quality of sleep included sleep quality during the week and the weekend, and sleep quality in general. Children also stated whether they like sleeping. Night-time fears implied feared objects, intensity of fear, and rumination.

\section{Other instruments}

\section{Children's Sleep Habits Questionnaire}

The CSHQ-DE 22,26 was used to correlate the Children's Sleep Comic score with the proxy rating by the parents. It consists of 52 items which are rated on a three-point 

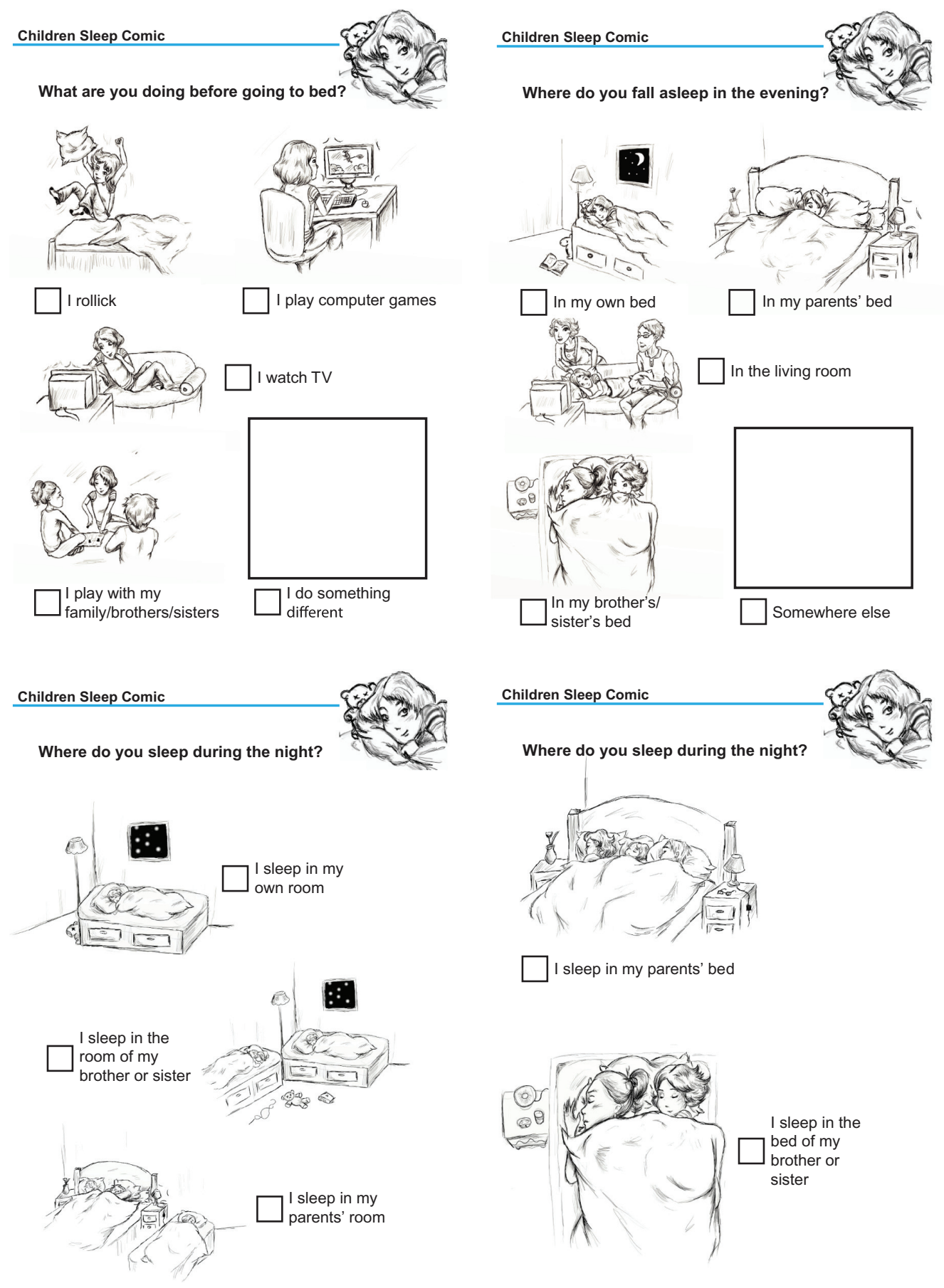

Figure I Example of items in the Children's Sleep Comic.

descriptive rating scale ( 1 rarely, 2 sometimes, 3 usually). Eight aspects of sleep behavior are assessed, ie, bedtime resistance, sleep onset delay, sleep duration, sleep anxiety, night wakings, parasomnias, sleep disordered breathing, and daytime sleepiness. The factor structure and psychometric properties of the CSHQ-DE were analyzed based on a healthy community sample $(n=298)$ and a clinical sample with sleep disorders $(n=45)$. Psychometric properties of the CSHQ-DE are very good (Cronbach's $\alpha=0.71$; retest-reliability $r=0.82) .{ }^{26}$ The subscale scores and total score differentiate between clinical and healthy samples on individual items, confirming construct validity. ${ }^{22,26} \mathrm{~A}$ wide range of studies using the CSHQ indicate the high acceptance and usability of this instrument. ${ }^{5,29-36}$ The CSHQ-DE can only be used as a screening instrument for sleep disorders. Validation of the CSHQ-DE and the CSHQ did not include comparisons with 
sleep laboratory or actigraphy data, so this method does have some limitations. ${ }^{22,26}$

\section{Sleep Self Report}

To relate the Children Sleep Comic score to another selfrating, we used the SSR-DE.,27 The SSR was constructed according to the CSHQ to allow for comparison of ratings made by the children and their parents. ${ }^{5}$ Children rate their sleep on a three-point descriptive rating scale (1 rarely, 2 sometimes, 3 usually) for 29 items which are summed up to a total score. The factor structure and psychometric properties of the SSR-DE were analyzed based on a healthy community sample $(n=211)$ and a clinical sample with sleep disorders $(n=48)$. The SSR-DE differentiated between these samples, confirming construct validity. The high reliability (Cronbach's $\alpha=0.73)^{37}$ and moderate retest-reliability $(\mathrm{r}=0.51)^{38}$ confirm that the SSR-DE is a good instrument for assessing sleep behavior in children. It is well accepted and clearly understood by children. ${ }^{5,39,40}$ The validation of the SSR-DE did not include comparisons with sleep laboratory or actigraphy data. ${ }^{27}$ Like the CSHQ-DE, the SSR-DE can only be used as a short screening instrument, and does not enable a clinical diagnosis to be made.

\section{Development of a score}

After generating the item-related cartoons (Figure 1), three independent experts rated the answer statements as supporting sleep or negatively affecting sleep. Some of the answers were also rated as neutral. Subsequent to the ratings, the experts discussed all statements until agreement was perfect. The items classified as interfering with sleep were summed to obtain an intensity-of-sleep problem score (ISPS). The ISPS indicates the extent of disturbed sleep. The highest possible score is 26 , and the higher the score, the more severe the sleep problem. To verify the ISPS, Pearson's rank correlations were calculated using the total scores for the SSR-DE and the CSHQ-DE. Also, the correlation between the total scores for the SSR-DE and the CSHQ-De was calculated to compare the concordance of children's and parents' ratings with those of previous comparisons between the two questionnaires. The Statistical Package for the Social Sciences version 18.0 for Windows (SPSS Inc, Chicago, IL) was used for the statistical analysis. Tests were two-tailed and the alpha level was $5 \%$.

\section{Results}

Application of the Children's Sleep Comic took an average of 30 minutes. The procedure was well accepted by the children and there were no dropouts, leaving 201 children for analysis. The sample comprised 103 girls and 98 boys, of mean age $8.58 \pm 1.13$ years. The mean age of the mothers was $40.27 \pm 5.21$ years and of the fathers was $42.77 \pm 5.33$ years. One hundred and sixty-six fathers and mothers worked full-time. One hundred and seventy-three children lived together with both parents, and 28 lived with a single parent (26 single mothers, two single fathers). The mean ISPS of the sample was $9.73 \pm 4.95$. The mean total CSHQ-DE score was $31.91 \pm 4.78$ and the mean total SSR-DE score was $29.08 \pm 6.78$.

The correlation between the total score of the SSR-DE and the ISPS was moderate $(\mathrm{r}=0.41, P<0.01)$, and the correlation between the total score of the CSHQ-DE and the ISPS was low $(\mathrm{r}=0.19, P<0.05)$. Correlation of the total scores for the SSR-DE and the CSHQ-DE was moderate (r $=0.46, P<0.01)$.

\section{Discussion}

The aim of this study was to develop a new assessment tool for sleep behavior and possible sleep disorders in children of a young age and to devise a first approach to calculate a total score. The strength of the Children's Sleep Comic is its applicability in young children, whereby children who are not yet able to read and write can be assessed. Older children can either use the cartoons for answering or read the accompanying text. Children are able to report freely about their sleep experiences at the age of three years, when supported by questions or hints. ${ }^{41}$ However, existing reports are vulnerable to the power of suggestion. Furthermore, developmental aspects can influence children's reporting. ${ }^{42}$ Thus, the Children's Sleep Comic can be helpful for assessment of young children, but interviewers should still be aware of the risk of suggestion.

The results of this study showed a moderate correlation between the total score of the SSR-DE and the ISPS. This indicates that the Children's Sleep Comic is a suitable instrument for assessing sleep disorders in children because its content is comparable but not equivalent to that of the SSR-DE. In comparison with the SSR-DE, the Children's Sleep Comic provides additional information about sleep hygiene and sleep-related anxieties. Differences in children's and parents' ratings about sleep behavior of the child are common. Thus, it is not surprising that the correlation between CSHQ-DE and ISPS was low. Consistent with earlier findings, the correlation between the total score on the SSR-DE and the total score on the CSHQ-DE was moderate. $^{27}$ 
These results further support the practice of including both children and their parents as part of the diagnostic process for sleep disorders, ${ }^{23,24}$ and are consistent with studies on pain and quality of life in children, which also indicate the need to assess parents and children. Children with sleep disorders usually report more severe symptoms (eg, headaches, somatic complaints, depressive symptoms) than their parents. ${ }^{43}$ Other results indicate good comparability for observable variables (eg, disabilities, family atmosphere), but not for internal experiences (eg, pain-related anxiety, depression). ${ }^{44}$ In addition, studies on quality of life have indicated that parents' and children's ratings complement each other, providing further evidence that both parents and children should be assessed. ${ }^{45-46}$ The Children's Sleep Comic accommodates this need.

To summarize, the Children's Sleep Comic is a new tool for assessing sleep and sleep-related behavior in young children, and is a first step toward bridging the gap between the wide range of reported prevalence rates of sleep disorders in young children and the instruments available for supporting proper diagnosis. Its diagnostic validity needs to be investigated. The German version of the Children Sleep Comic will be soon freely available from the author's homepage. Work in progress includes an English translation.

\section{Acknowledgments}

This publication was funded by the German Research Foundation and the University of Würzburg under the Open Access Publishing funding program. We thank the deans of the participating schools and teachers for their support, and especially the children and parents who took part in this study.

\section{Disclosure}

The authors report no conflicts of interest in this work.

\section{References}

1. Kahn A, Van de Merckt C, Rebuffat E, Mozin MJ, Sottiaux M, Blum D. Sleep problems in healthy preadolescents. Pediatrics. 1989;84(3): 542-546.

2. Archbold KH, Pituch KJ, Panahi P, Chervin RD. Symptoms of sleep disturbances among children at two general pediatric clinics. J Pediatr. 2002;140(1):97-102.

3. Paavonen EJ, Aronen ET, Moilanen I, et al. Sleep problems of school-aged children: a complementary view. Acta Paediatr. 2000;89(2):223-228.

4. Rona RJ, Li L, Gulliford MC, Chinn S. Disturbed sleep: effects of sociocultural factors and illness. Arch Dis Child. 1998;78(1):20-25.

5. Owens JA, Spirito A, McGuinn M, Nobile C. Sleep habits and sleep disturbance in elementary school-aged children. J Dev Behav Pediatr. 2000;21(1):27-36.
6. Schlarb AA, Hust C, Hautzinger M. Psychological factors and treatment of adolescents with insomnia [Psychologische Faktoren und Behandlung von Jugendlichen mit Insomnie]. Pädiatr Praxis. 2009;74:719-430. German.

7. Chervin RD, Dillon JE, Bassetti C, Ganoczy DA, Pituch KJ. Symptoms of sleep disorders, inattention, and hyperactivity in children. Sleep. 1997;20(12):1185-1192.

8. Gregory AM, Van der Ende J, Willis TA, Verhulst FC. Parentreported sleep problems during development and self-reported anxiety/ depression, attention problems, and aggressive behavior later in life. Arch Pediatr Adolesc Med. 2008;162(4):330-335.

9. Lehmkuhl G, Fricke-Oerkermann L, Wiater A, Mitschke A. Sleep disorders in children beginning school: their causes and effects. Dtsch Arztebl Int. 2008;105(47):809-814.

10. Gozal D, Wang M, Pope DW. Objective sleepiness measures in pediatric obstructive sleep apnea. Pediatrics. 2001;108(3):693-697.

11. O'Brien EM, Mindell JA. Sleep and risk-taking behavior in adolescents. Behav Sleep Med. 2005;3(3):113-133.

12. Paavonen EJ, Solantaus T, Almqvist F, Aronen ET. Four-year follow-up study of sleep and psychiatric symptoms in preadolescents: relationship of persistent and temporary sleep problems to psychiatric symptoms. J Dev Behav Pediatr. 2003;24(5):307-314.

13. Levers-Landis CE, Storfer-Isser A, Rosen C, Johnson NL, Redline S. Relationship of sleep parameters, child psychological functioning, and parenting stress to obesity status among preadolescent children. $J$ Dev Behav Pediatr. 2008;29(4):243-252.

14. Lumeng JC, Somashekar D, Appugliese D, Kaciroti N, Corwyn RF, Bradley RH. Shorter sleep duration is associated with increased risk for being overweight at ages 9 to 12 years. Pediatrics. 2007;120(5): 1020-1029.

15. Snell EK, Adam EK, Duncan GJ. Sleep and the body mass index and overweight status of children and adolescents. Child Dev. 2007;78(1): 309-323.

16. Johnson EO, Chilcoat HD, Breslau N. Trouble sleeping and anxiety/ depression in childhood. Psychiatry Res. 2000;94(2):93-102.

17. Lam P, Hiscock H, Wake M. Outcomes of infant sleep problems: a longitudinal study of sleep, behavior, and maternal well-being. Pediatrics. 2003;111(3):e203-e207.

18. Riemann D, Voderholzer U. Primary insomnia: a risk factor to develop depression? J Affect Disord. 2003;76(1-3):255-259.

19. Mindell JA. Sleep disorders in children. Health Psychol. 1993;12(2): $151-162$.

20. Mindell JA, Moline ML, Zendell SM, Brown LW, Fry JM. Pediatricians and sleep disorders: training and practice. Pediatrics. 1994;94(2 Pt 1): 194-200.

21. Schlarb AA, Gulewitsch MD, Hautzinger M. Insomnia in pediatric care [Insomnien in der pädiatrischen Praxis]. Somnologie. 2011;14:129-134. German

22. Owens JA, Spirito A, McGuinn M. The Children's Sleep Habits Questionnaire (CSHQ): psychometric properties of a survey instrument for school-aged children. Sleep. 2000;23(8):1043-1051.

23. Schwerdtle B, Isele D, Schlarb AA, Kübler A. Child health-related quality of life in relation to sleep behavior: a comparison between parental- and self-rating. In preparation.

24. Spruyt K, Gozal D. Pediatric sleep questionnaires as diagnostic or epidemiological tools: a review of currently available instruments. Sleep Med Rev. 2011;15(1):19-32.

25. Rabenschlag U. "Freiburger Kinderschlafcomic" for children [Freiburger Kinderschlafcomic für Kinder]. University of Freiburg, Germany: unpublished questionnaire; 1992. German.

26. Schlarb AA, Schwerdtle B, Hautzinger M. Validation and psychometric properties of the German version of the Children's Sleep Habits Questionnaire (CSHQ-DE). Somnologie. 2010;14(4):260-266.

27. Schwerdtle B, Roeser K, Kübler A, Schlarb AA. Validation and psychometric properties of the German version of the Sleep Self Report (SSR-DE) [Validierung und psychometrische Eigenschaften der deutschen Version des Sleep Self Report (SSR-DE)]. Somnologie. 2010;14(4):267-274. German. 
28. American Academy of Sleep Medicine. The International Classification of Sleep Disorders: Diagnostic and Coding Manual. 2nd ed. Westchester, IL; 2005.

29. Honomichl RD, Goodlin-Jones BL, Burnham M, Gaylor E, Anders TF. Sleep patterns of children with pervasive developmental disorders. J Autism Dev Disord. 2002;32(6):553-561.

30. Owens JA, Maxim R, Nobile C, McGuinn M, Msall M. Parental and self-report of sleep in children with attention-deficit/hyperactivity disorder. Arch Pediatr Adolesc Med. 2000;154(6):549-555.

31. Gaina A, Sekine M, Chen X, Hamanishi S, Kagamimori S. Validity of child sleep diary questionnaire among junior high school children. J Epidemiol. 2004;14(1):1-4.

32. Liu X, Liu L, Owens JA, Kaplan DL. Sleep patterns and sleep problems among schoolchildren in the United States and China. Pediatrics. 2005;115(Suppl 1):241-249.

33. Liu X, Liu L, Wang R. Bed sharing, sleep habits, and sleep problems among Chinese school-aged children. Sleep. 2003;26(7):839-844.

34. Miller VA, Palermo TM, Powers SW, Scher MS, Hershey AD. Migraine headaches and sleep disturbances in children. Headache. 2003;43(4): 362-368.

35. Goodlin-Jones BL, Sitnick SL, Tang K, Liu L, Anders TF. The Children's Sleep Habits Questionnaire in toddlers and preschool children. J Dev Behav Pediatr. 2008;29(2):82-88.

36. Giannotti F, Cortesi F, Sebastiani T, Vagnoni C. Sleeping habits in Italian children and adolescents. Sleep Biol. 2005;3(1):15-21.

37. Kline P. The Handbook of Psychological Testing. 2nd ed. London, UK: Routledge; 1999.

38. Brosius F. SPSS 11. Bonn, Germany: MIPT Verlag; 2002.
39. Bloom BJ, Owens JA, McGuinn M, Nobile C, Schaeffer L, Alario AJ. Sleep and its relationship to pain, dysfunction, and disease activity in juvenile rheumatoid arthritis. J Rheumatol. 2002;29(1):169-173.

40. Gregory AM, Rijsdijk FV, Eley TC. A twin-study of sleep difficulties in school-aged children. Child Dev. 2006;77(6):1668-1679.

41. Roebers CM, Elischberger HB. Autobiographical memories of young children: possibilities and limitations for their free reports [Autobiographische Erinnerung bei jungen Kindern: Möglichkeiten und Grenzen bei der Verbesserung ihrer freien Berichte]. Z Entwickl Pädagogis. 2002;32:2-10. German.

42. Cordon IM, Saetermoe CL, Goodman GS. Facilitating children's accurate responses: conversational rules and interview style. Appl Cogn Psychol. 2005;19:249-266.

43. Kroner-Herwig B, Morris L, Heinrich M, Gassmann J, Vath N. Agreement of parents and children on characteristics of pediatric headache, other pains, somatic symptoms, and depressive symptoms in an epidemiologic study. Clin J Pain. 2009;25(1):58-64.

44. Cohen LL, Vowles KE, Eccleston C. Adolescent chronic pain-related functioning: concordance and discordance of mother-proxy and selfreport ratings. Eur J Pain. 2010;14(8):882-886.

45. Eiser C, Morse R. Can parents rate their child's health-related quality of life? Results of a systematic review. Qual Life Res. 2001;10(4): 347-357.

46. Klassen AF, Miller A, Fine S. Agreement between parent and child report of quality of life in children with attention-deficit/hyperactivity disorder. Child Care Health Dev. 2006;32(4):397-406.
Nature and Science of Sleep

\section{Publish your work in this journal}

Nature and Science of Sleep is an international, peer-reviewed, open access journal covering all aspects of sleep science and sleep medicine, including the neurophysiology and functions of sleep, the genetics of sleep, sleep and society, biological rhythms, dreaming, sleep disorders and therapy, and strategies to optimize healthy sleep. The journal welcomes

\section{Dovepress}

original research, clinical \& epidemiological studies, reviews \& evaluations, case reports and extended reports. The manuscript management system is completely online and includes a very quick and fair peerreview system, which is all easy to use. Visit http://www.dovepress.com/ testimonials.php to read real quotes from published authors. 